Revue d'histoire de l'Amérique française

REYUE D.HISTOIRE DE L'AMÉRIQUE FRANÇAISE

\title{
CHAMBERLAND, Nicole, Jane McLEOD, Christine TURGEON, sous la direction de Raymonde LITALIEN, Amirauté de Guyenne, source de l'histoire de la Nouvelle-France : (série 6B), Archives départementales de la Gironde, Bordeaux, France. Ottawa, Archives nationales du Canada, 1993. 99 p. Annexe.
}

\section{Étienne Taillemite}

Volume 48, numéro 1, été 1994

URI : https://id.erudit.org/iderudit/305319ar

DOI : https://doi.org/10.7202/305319ar

Aller au sommaire du numéro

Éditeur(s)

Institut d'histoire de l'Amérique française

ISSN

0035-2357 (imprimé)

1492-1383 (numérique)

Découvrir la revue

Citer ce compte rendu

Taillemite, É. (1994). Compte rendu de [CHAMBERLAND, Nicole, Jane McLEOD, Christine TURGEON, sous la direction de Raymonde LITALIEN, Amirauté de Guyenne, source de l'histoire de la Nouvelle-France : (série 6B), Archives départementales de la Gironde, Bordeaux, France. Ottawa, Archives nationales du Canada, 1993. 99 p. Annexe.] Revue d'histoire de l'Amérique française, 48(1), 119-119. https://doi.org/10.7202/305319ar d'utilisation que vous pouvez consulter en ligne. 
CHAMBERLAND, Nicole, Jane McLEOD, Christine TURGEON, sous la direction de Raymonde LITALIEN, Amirauté de Guyenne, source de l'histoire de la Nouvelle-France: (série 6B), Archives départementales de la Gironde, Bordeaux, France. Ottawa, Archives nationales du Canada, 1993. 99 p. Annexe.

Les fonds d'archives des amirautés françaises, pourtant riches, ont encore assez peu attiré l'attention des chercheurs. Il faut donc féliciter les Archives nationales du Canada d'avoir mis à leur programme une exploration systématique de certains d'entre eux qui présentent un vif intérêt pour l'histoire des relations entre l'Europe et l'Amérique. Le fonds de l'Amirauté de Guyenne conservé à Bordeaux en est un excellent exemple, et il sera désormais facilement accessible aux historiens grâce au présent guide qui ne laisse rien à désirer. Fruit d'un travail de près de dix ans, il nous donne en premier lieu une excellente introduction analysant les rouages de l'institution, son histoire, ses relations avec l'Amirauté de France, sa compétence au civil et au criminel, son fonctionnement, son personnel avec la liste des lieutenants généraux et des procureurs du roi.

Vient ensuite une présentation très précise du fonds qui ne remonte pas au-delà de 1640 bien que l'Amirauté ait été créée en 1490. L'institution possédait, on le sait, des attributions administratives et judiciaires. Les premières concernent, outre des textes législatifs, les nombreux documents relatifs à la navigation marchande: réceptions, soumissions, lettres de mer, déclarations diverses, visites de navires, accidents, etc. Les secondes donnent lieu aux procédures variées liées au contentieux de la vie maritime: informations, inventaires, sentences, ventes, etc. La masse des papiers judiciaires est nettement plus importante que celle des papiers administratifs: 1500 articles environ contre 612 . Tous les types de documents sont analysés et présentés avec soin, et on y a heureusement joint un glossaire des termes de droit et de marine, une liste des toponymes anciens et une bibliographie. Avec le répertoire numérique, l'ensemble est complet et constitue un remarquable instrument de recherche dont il convient de féliciter les auteurs. 